\title{
Distance Relay Protection Improvement of Alaoji-Afam 330kV Transmission Line
}

\author{
Eseosa Omorogiuwa, and Wonodi Ikonwa
}

\begin{abstract}
Fault resistance influences the operation of distance relays, thus causing it to give inaccurate impedance measurement, thus resulting to under-reach condition. Trip report of fault occurrence in Alaoji-Afam $330 \mathrm{kV}$ line showed the effect of fault resistance on the relay operation. This paper seeks to improve distance relay performance in terms of reliability, speed and selectivity on Alaoji-Afam $330 \mathrm{kV}$ transmission line, when fault resistance is present through adjustment of protected zone reach using NEPLAN software to model and simulate distance relay used for this study. Several simulations were run, and the results showed good improvement of distance relay operation in handling fault conditions. Adjustment of the protected zone reach was done to compensate for the effect of high fault resistance on distance relay operation.
\end{abstract}

Index Terms-Afam-Alaoji; NEPLAN; Protection Relay; $330 \mathrm{kV}$.

\section{INTRODUCTION}

Power system consists of network of generators, transformers, transmission/distribution lines etc and usually experience short circuits and other abnormalities due to large flow of fault current in the system equipment, resulting to damage to lives and properties if allowed to stay for long period. These equipment are protected from abnormalities using appropriate protection schemes which consist of Current/Voltage Transformers (CTs/VTs), circuit breakers and protective relays. Protective relays act as the brain of any protective system which with the help of current and voltage transformers senses the abnormalities in power system network and coordinates circuit breakers whether to trip or not. Occurrence of faults could result in poor relay coordination thus leading to short circuit. Short circuits are commonly known as Fault and may be 3-phase, double line, single line to ground as well as double line to ground faults and usually occur in power system no matter how well it is designed. Its effect could result to loss of synchronization. During fault occurrence, automatic protective equipment is required to operate to isolate faulty section(s). Distance relay protection is used for transmission line protection and it is based on electrical measurement of distance along transmission line to fault point as its impedance are uniformly distributed along the line length. This provides the basis for the principle of operation of distance relay. Distance relaying is considered where over current relay is so slow to adopt or is not selective. Discrimination,

Published on September 30, 2018.

E. Omorogiuwa and W. Ikonwa are with the Electrical/Electronic Engineering, Faculty of Engineering, University of Port Harcourt, Rivers State, Nigeria (e-mail: eseosa.omorogiuwa@uniport.edu.ng, oomorogiuwa@yahoo.com). selectivity, and speed of operation can be obtained by distance protection by allowing trip operation up to a certain range of distance and comprises of both primary and backup protections which operates when the primary protection fails. Distance Protection Scheme (DPS) comprises of three or more sets of distance protection zones positioned one behind the other. To find out if the fault is within or outside the protected zone, distance relay does a comparison of the setting impedance and the measured impedance and immediately releases trip signal when the impedance value is inside zone one impedance circle of distance relay [1].

Performance of distance relay is measured using criteria such as reliability, speed, selectivity etc. However, distance relays protecting Alaoji/Afam 330kV transmission lines was observed through the study of fault trip report obtained from the substation, that the relay did not operate correctly at certain times, showing deficiency in reliability, inaccurate measurement of fault impedance and wrong zone indication. This problem is due to presence of fault resistance which caused the distance relay to under reach. It was also observed that the relay is not selective and has poor fault discrimination (i.e it could not distinguish between faults between both protected and outside the protected line). It did not operate fast and thus shows deficiency in speed. Faults in the protected region were detected in zone two. These observations show that the distance relay protection in Alaoji substation requires improvement. Therefore, this work focuses on improving the performance of distance relay protection scheme protecting Alaoji/Afam $330 \mathrm{kV}$ transmission lines, with regards to reliability, speed and selectivity by compensating for the effects of additional fault resistance introduced due to arcing, which is largely the cause of incorrect operation of distance relay. This is done to ensure safety of expensive power system equipment/personnel working at the station. Design Models using NEPLAN simulation software are used to examine distance relay performance during fault occurrence and these changes are in terms of current, voltage, frequency and phase angle. The specific objectives of study are:

$>$ To study fault trip report of distance relays installed in Alaoji 330kV substation.

$>$ To model distance relay protection scheme to detect and clear three-phase and single-line to ground faults on Alaoji-Afam 330kV transmission lines.

$>$ To simulate distance relay model to show its performance during 3-phase and one-line to ground faults with and without additional fault resistance.

$>$ To compensate for the effects of high fault resistance on distance relay operation. 


\section{LITERATURE REVIEW}

Reference [1] defined distance protection and gave some differences between distance relays and over-current relays. Distance protection involves the electrical measurement of distance along a transmission line to the fault point. There is uniform distribution of the impedance of the transmission line along the length of the transmission line. The impedance from the relay to the fault point is proportional to the distance from the relay to the fault point. Therefore, this is the basis of the principle of distance relay. Unlike overcurrent protection, distance relay protection gives a good way of having selectivity, speed of operation and discrimination by allowing trip operation up to a particular measure of distance. Over-current protection has no backup protection. However, in distance protection, three sets of distance protection zones are set up to provide back up. Fault coverage of over-current protection is affected by source impedance variations, but fault coverage of distance protection is not affected by source impedance variation. Reference [2] investigated and concluded that the basis of network protection in transmission is distance protection. Relative source impedances and system conditions do not easily affect distance protection. According to [3], distance relay characteristics are of various types which includes mho, quadrilateral, reactance, admittance, polarized-mho, offset mho etc. Reference [3] researched on distance relay modeling and simulation for performance testing using MATLAB/SIMULINK tool using MHO distance characteristics and analyzed the relay for one-phase to ground and three phase faults at $20 \mathrm{~km}$ and $49 \mathrm{~km}$ of the line length and found that the relay operated correctly but when a $5 \Omega$ fault resistance was introduced at $20 \mathrm{~km}$ of the line length, the relay under-reached. Furthermore, it was found that power system networks regularly encounter short circuits such as trees falling on lines and other abnormal conditions that make current leave the intended path to flow through another path. Because of this short circuit, heavy current flows in the power system equipment thereby causing damage to them. Reference [1] described distance relay performance using MATLAB/SIMULINK for testing. Relay model using MHO distance characteristic for three phase and one-phase to ground fault at certain distance was investigated at $80 \%$ of the line and found out that the relay operated correctly. These researchers further explained that since power system is regarded as large capital investment because most of its equipment are very costly, there must be security and reliability of supply for the entire power system to be optimally utilized as power system always encounter faults despite how well it was designed. The brain of any protective system is the protective relay while transducers help to sense network abnormalities and then relate it to the protective relay. Circuit breakers receives trip signal from the protective relay to isolate faulty parts from healthy part. Reference [4] implemented Mho type distance relay model with three zones of protection by using MATLAB/SIMULINK tool for performance testing. Model simulation for one-phase to ground faults, line-line to ground faults and three phase faults at locations of $70 \mathrm{~km}$, $115 \mathrm{~km}$ and $210 \mathrm{~km}$ was investigated and found out that the relay operated correctly. According to [5], distance relays measure the line impedance from the position of the relay up to the fault point. This measured impedance is proportional to the line length from the position of the relay to the fault point.

Values of three phase currents and voltages from VTs/CTs are inputs for impedance measurement. These three phase voltages and currents require filtering to clear off the harmonics which may be present due to arcing of the fault. Sampling of filtered signals at required/selected sampling frequency is done before being used by distance relay. The relay then compares the setting impedance with the impedance measured to ascertain if the fault is within or outside the protected zone. Reference [6] analyzed the performance of relays and protection systems and proffer the most economic and feasible way to model protective relay. In their paper, PSCAD/EMTDC software was used to model and simulate MHO characteristics mode of distance relay. Only one-phase to ground fault at different zones with fault resistance and without fault resistance to examine relay performance was considered using $230 \mathrm{kV}, 300 \mathrm{~km}$ transmission line system. SLG fault without fault resistance at $60 \mathrm{~km}, 20 \mathrm{~km}$ and $12 \mathrm{~km}$ distance from bus- A, B and C positions were simulated respectively. One-phase to ground fault with $10 \Omega$ fault resistance at $60 \mathrm{~km}$ from the position of bus A was also simulated and the result shows that the fault was detected by the relay in zone 2 instead of zone 1 . Fault resistance increase caused the relay to detect the fault in zone 3 instead of zone 1. Thus, showing that distance relay under reaches due to fault resistance. Reference [7] defined sampling as the process of changing continuous time signals to a discrete time signals. Analog and digital signals must be considered when selecting the sampling rate or frequency. This is to ensure that discrete time signals generated or sampled clearly represent continuous time signal.

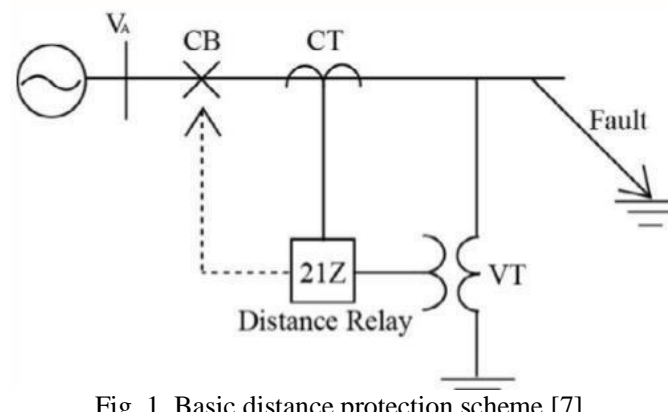

\section{A. Mho Characteristics}

Mho type distance relay characteristic protects long transmission line. It is characteristic of circle A, B, C and D. Three zone mho characteristics is shown below.

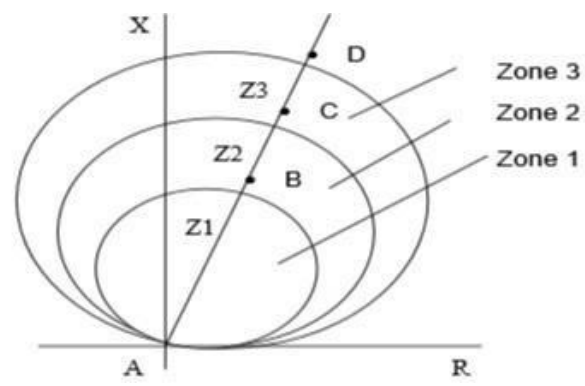

Fig. 2. Three zone Mho Characteristics [8] 


\section{B. Fault Calculation Algorithm}

Faults could either be symmetrical or asymmetrical faults. Three phase fault is the only symmetrical fault and it has all phases in contact with each other. Unsymmetrical faults include 2-phase (L-L) fault, 2-phase to ground (LL-G), and 1-phase to ground (SLG) faults [9]. According to [10], when transmission lines experience abnormal conditions, fault impedance is measured by the relay between faulted phases in case of L-L fault or between phases under fault and neutral line in case of earth faults. The table below shows the various algorithms used in the measurement of fault impedance for various types of fault.

TABLE I: DIFFERENT FAULT TYPES IMPEDANCE ALGORITHM [11]

\begin{tabular}{ll}
\hline \hline Fault Type & Algorithm \\
\hline AG & $\mathrm{V}_{\mathrm{A}} /\left(\mathrm{I}_{\mathrm{A}}+3 \mathrm{k}_{0} \mathrm{I}_{0}\right)$ \\
$\mathrm{BG}$ & $\mathrm{V}_{\mathrm{B}} /\left(\mathrm{I}_{\mathrm{B}}+3 \mathrm{k}_{0} \mathrm{I}_{0}\right)$ \\
$\mathrm{CG}$ & $\mathrm{V}_{\mathrm{C}} /\left(\mathrm{I}_{\mathrm{C}}+3 \mathrm{k}_{0} \mathrm{I}_{0}\right)$ \\
AB or ABG & $\left(\mathrm{V}_{\mathrm{A}}-\mathrm{V}_{\mathrm{B}}\right) /\left(\mathrm{I}_{\mathrm{A}}-\mathrm{I}_{\mathrm{B}}\right)$ \\
$\mathrm{BC}$ or BCG & $\left(\mathrm{V}_{\mathrm{B}}-\mathrm{V}_{\mathrm{C}}\right) /\left(\mathrm{I}_{\mathrm{B}}-\mathrm{I}_{\mathrm{C}}\right)$ \\
$\mathrm{CA}$ or CAG & $\left(\mathrm{V}_{\mathrm{C}}-\mathrm{V}_{\mathrm{A}}\right) /\left(\mathrm{I}_{\mathrm{C}}-\mathrm{I}_{\mathrm{A}}\right)$ \\
ABC & $\mathrm{V}_{\mathrm{A}} / \mathrm{I}_{\mathrm{A}}$ \\
\hline \hline
\end{tabular}

where; $A, B$ and $C$ indicates faulty phases, $V_{A}, V_{B}$ and $V_{C}$ are voltage phasors while $\mathrm{I}_{\mathrm{A}}, \mathrm{I}_{\mathrm{B}}$ and $\mathrm{I}_{\mathrm{C}}$ are current phasors. $\mathrm{Z}_{0}=$ line zero-sequence impedance $\mathrm{Z}_{1}=$ line positivesequence impedance $\mathrm{k}_{0}=$ residual compensation factor where $\mathrm{k}_{0}=\left(\mathrm{Z}_{0}-\mathrm{Z}_{1}\right) / 3 \mathrm{Z}_{1}$. Reference [11] considers the circuit shown in Fig. 3. There are fault types in this system: A-G, B-G, C-G, AB, BC, CA, AB-G, BC-G, CA-G, ABC, and $\mathrm{ABC}-\mathrm{G}$. The path followed by fault current from source to fault location and back to source is the fault loop.

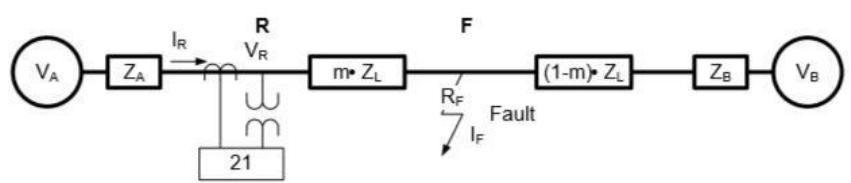

Fig. 3. Transmission line [12]

At the relay location $(\mathrm{R})$ the voltages can be expressed as functions of relay currents and voltages at the fault point $(F)$. By using symmetrical components, the following equations can be written:

$$
\begin{aligned}
& V_{1 R}-I_{1 R} \cdot m \cdot Z_{1 L}-V_{1 F}=0 \\
& V_{2 R}-I_{2 R} \cdot m \cdot Z_{1 L}-V_{2 F}=0 \\
& V_{0 R}-I_{0 R} \cdot m \cdot Z_{0 L}-V_{0 F}=0
\end{aligned}
$$

Adding (1), (2), and (3) produces:

$$
V_{1 R}+V_{2 R}+V_{0 R}-I_{1 R} \cdot m \cdot Z_{1 L}-I_{2 R} \cdot m \cdot Z_{1 L}-I_{0 R} \cdot m \cdot Z_{0 L}-
$$$$
V_{1 F}-V_{2 F}-V_{0 F}=0
$$

Assuming an AG fault and recognizing that:

$$
\begin{aligned}
& V_{1 R}+V_{2 R}+V_{0 R}=V_{A R} \\
& V_{1 F}+V_{2 F}+V_{0 F}=I_{F} \cdot R_{F}
\end{aligned}
$$

$V_{A R}-m \cdot Z_{1 L} \cdot\left(I_{1 R}+I_{2 R}+\left(\frac{Z_{0 L}}{z_{1 L}}\right) \cdot I_{0 R}\right)-I_{F} \cdot R_{F}=0$

Add and subtract the zero-sequence current at the relay:

$V_{A R}-m \cdot Z_{1 L} \cdot\left(I_{1 R}+I_{2 R}+I_{0 R}-I_{0 R}+\left(\frac{Z_{0 L}}{Z_{1 L}}\right) \cdot I_{0 R}\right)-$

$I_{F} \cdot R_{F}=0$

$I_{1 R}+I_{2 R}+I_{0 R}=I_{A R}$

Equation (8) is re-written as follows:

$V_{A R}-m \cdot Z_{1 L} \cdot\left(I_{A R}+I_{0 R}\left(\left(\frac{Z_{0 L}}{z_{1 L}}\right)-1\right)\right)-I_{F} \cdot R_{F}=0$

The compensated current is given as:

$$
\begin{aligned}
& I_{A G R}=I_{A R}+I_{0 R}\left(\left(\frac{z_{0 L}}{z_{1 L}}\right)-1\right)=I_{A R}+K_{0} \cdot I_{0 R} \\
& V_{A R}-m \cdot Z_{1 L} \cdot\left(I_{A R}+K_{0} \cdot I_{0 R}\right)=I_{F} \cdot R_{F}
\end{aligned}
$$

When $\mathrm{R}_{\mathrm{F}}$ is zero, then equation (12) is as follows:

$V_{A R}-m \cdot Z_{1 L} \cdot\left(I_{A R}+K_{0} \cdot I_{0 R}\right)=0$

$m \cdot Z_{1 L}=\frac{V_{A R}}{\left(I_{A R}+K_{0} \cdot I_{0 R}\right)}$

Ideally, apparent impedance $\mathrm{V}_{\mathrm{A}} /\left(\mathrm{I}_{\mathrm{A}}+\mathrm{k}_{0} \cdot \mathrm{I}_{0}\right)$ for ground fault is equal to positive sequence impedance between the relay and fault point and proportional to distance to the fault. $\mathrm{m}=$ fault location estimation (in per unit), $\mathrm{V}_{1 \mathrm{R}}, \mathrm{V}_{2 \mathrm{R}}, \mathrm{V}_{0 \mathrm{R}}=$ positive, negative and zero sequence voltages respectively at the relay location, $\mathrm{I}_{1 \mathrm{R}}, \mathrm{I}_{2 \mathrm{R}}, \mathrm{I}_{0 \mathrm{R}}=$ positive, negative and zero sequence currents respectively at the relay location, $\mathrm{V}_{1 \mathrm{~F}}, \mathrm{~V}_{2 \mathrm{~F}}$, $\mathrm{V}_{0 \mathrm{~F}}=$ positive, negative and zero sequence voltages respectively at the fault point, $Z_{1 \mathrm{~L}}=$ positive sequence impedance, $\mathrm{Z}_{\mathrm{OL}}=$ zero sequence impedance, $\mathrm{K}_{0}=$ residual current compensation factor, $\mathrm{I}_{\mathrm{A}}=$ phase current at the relay location, $\mathrm{V}_{\mathrm{A}}=$ phase to ground voltage at the relay location, $\mathrm{R}_{\mathrm{F}}=$ fault resistance.

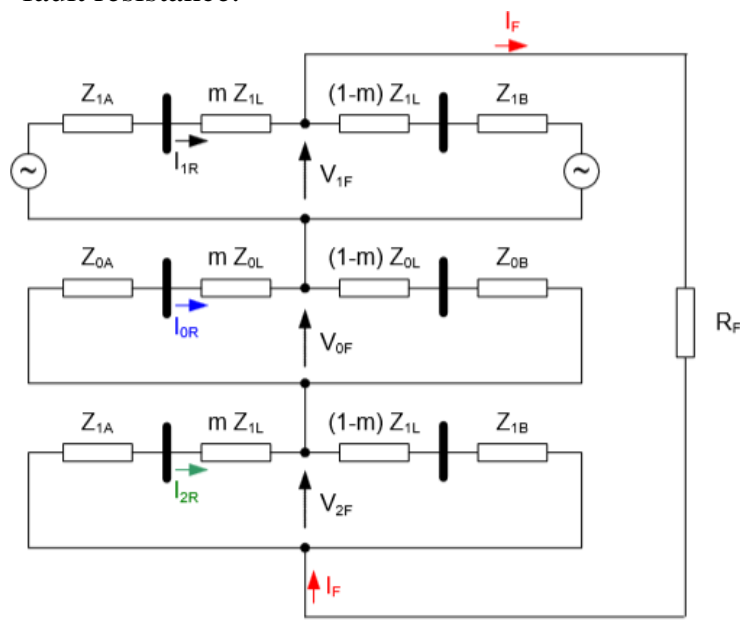

Fig. 4. Equivalent diagram for 1-phase-to-ground faults

Equation (5) can be written as follows: 


\section{METHODOLOGY}

$>$ Review past works on distance relay protection scheme

$>$ Visit to Alaoji substation for fault trip report showing performance of distance relays over six months' period

$>$ Study, model and simulate distance relay using the NEPLAN software.

Electricity generating authority has the task of maintaining continuous supply of electrical energy to consumers. Discrimination between normal and faulted conditions in power system is done by protective relays. When fault occurs, it should operate speedily. Voltage signal from the voltage transformer and current from the current transformer used for voltage measurement during the periods of fault occurrence may contain transient errors which distort the accuracy of the relay. Mal-operation of distance relays can give rise to large disturbance in the electricity supply system.

\section{A. Data Sources}

System parameters such as relay and transmission lines were collected from Alaoji substation Protection, Electrical maintenance and System operations departments. The operation of protective relay scheme requires extensive analysis in order to determine its performance. Therefore, it is important in this research work to study and present the performance of existing distance relay in Alaoji $330 \mathrm{kV}$ substation. This is done through distance relay trip report in Table II. This gives report of voltages and currents phases at the relaying point during fault occurrence. It also shows faulted phase, fault location and circuit breaker status (BK1 and BK2).

From the relay trip report of Table II, fault report number 1 shows that fault occurred at $21.66 \mathrm{~km}$ and in zone 1 . This is wrong as zone 1 which is set to be $80 \%$ of the line is less than $21.66 \mathrm{~km}$. Also, from trip report 2, fault occurred at $24.92 \mathrm{~km}$ and the relay indicated zone 1 , which is wrong. Trip report number 3,4 and 9 shows that fault occurred at $16.67 \mathrm{~km}, 19 \mathrm{~km}$ and $11.45 \mathrm{~km}$ respectively, and the relay indicated zone 2. This also, is wrong. These are clear indications that the relaying scheme in Alaoji substation lacks the quality of selectivity. It could not differentiate between fault in zone 1 and fault outside zone 1. This is because of high fault resistance present on the line causing the distance relay to under-reach.

TABLE II: ALAOJI - AFAM 330KV LINE DISTANCE RELAY TRIP REPORT

\begin{tabular}{|c|c|c|c|c|c|c|c|c|c|c|}
\hline $\mathrm{S} / \mathrm{N}$ & Date & $\begin{array}{l}\text { Fault } \\
\text { Location } \\
(\mathrm{Km})\end{array}$ & $\begin{array}{l}\text { Target } \\
\text { Zone }\end{array}$ & $\begin{array}{l}\text { Circuit } \\
\text { Breaker }\end{array}$ & $\begin{array}{l}\text { Phase A } \\
\text { Voltage } \\
(\mathrm{kV})\end{array}$ & $\begin{array}{l}\text { Phase B } \\
\text { Voltage } \\
(\mathrm{kV})\end{array}$ & $\begin{array}{l}\text { Phase C } \\
\text { Voltage }(\mathrm{kV})\end{array}$ & $\begin{array}{l}\text { Phase A } \\
\text { Current (kA) }\end{array}$ & $\begin{array}{l}\text { Phase B } \\
\text { Current (kA) }\end{array}$ & $\begin{array}{l}\text { Phase C } \\
\text { Current (kA) }\end{array}$ \\
\hline 1 & $1 / 9 / 2017$ & 24.92 & $\begin{array}{l}\text { Zone } 1 \\
\text { A-GND }\end{array}$ & $\begin{array}{l}\text { BK 1\&2 } \\
\text { Open }\end{array}$ & $27 \angle 9.5$ & $\begin{array}{l}110 \angle- \\
122.5\end{array}$ & $29 \angle 67.9$ & $2114 \angle-67$ & $344 \angle 129.6$ & $\begin{array}{l}374 \angle \\
42\end{array}$ \\
\hline 2 & $2 / 1 / 2017$ & 16.67 & $\begin{array}{l}\text { Zone } 2 \\
\text { A-GND }\end{array}$ & $\begin{array}{l}\text { BK } 1 \& 2 \\
\text { Open }\end{array}$ & $32 \angle-34$ & $\begin{array}{l}157 \angle- \\
108.8\end{array}$ & $161 \angle 109$ & $2232 \angle-82.7$ & $411 \angle 67.9$ & $343 \angle-66.6$ \\
\hline 3 & $4 / 09 / 2016$ & 19 & $\begin{array}{l}\text { Zone } 2 \\
\text { C-GND }\end{array}$ & $\begin{array}{l}\text { BK 1\&2 } \\
\text { Open }\end{array}$ & $191 \angle 0.7$ & $\begin{array}{l}191 \angle- \\
119.3\end{array}$ & $33 \angle 120.8$ & $1 \angle 48.8$ & $1 \angle-63.2$ & $3201 \angle 42.4$ \\
\hline 4 & $19 / 5 / 2016$ & 17.56 & $\begin{array}{l}\text { Zone } 1 \\
\text { A\&C- } \\
\text { GND }\end{array}$ & $\begin{array}{l}\text { BK 1\& } \\
\text { 2-Open }\end{array}$ & $27 \angle 11.3$ & $\begin{array}{l}108 \angle- \\
122.3\end{array}$ & $29 \angle 69.1$ & $2160<-83.2$ & $341 \angle 126.2$ & $3893 \angle 32.3$ \\
\hline 5 & $9 / 4 / 2016$ & 21.66 & $\begin{array}{l}\text { Zone } 1 \\
\text { C-GND }\end{array}$ & $\begin{array}{l}\text { BK1\&2- } \\
\text { Open }\end{array}$ & $163 \angle 18.6$ & $\begin{array}{l}164 \angle- \\
142.4\end{array}$ & $28 \angle 105.6$ & $444 \angle-139.3$ & $504 \angle-138.9$ & $2572 \angle 41.2$ \\
\hline 6 & $9 / 3 / 2016$ & 27.15 & $\begin{array}{l}\text { Zone } 2 \\
\text { A\&B- } \\
\text { Phases }\end{array}$ & $\begin{array}{l}\text { BK 1\& 2- } \\
\text { Open }\end{array}$ & $96<-50.6$ & $96<-67.9$ & $191 \angle 120.7$ & $1607 \angle-53.9$ & $1605 \angle-126.2$ & $0<-110.1$ \\
\hline 7 & 4/1/2016 & 32.24 & $\begin{array}{l}\text { Zone } 3 \\
\text { C-GND }\end{array}$ & $\begin{array}{l}\text { BK 1\& 2- } \\
\text { Open }\end{array}$ & $160 \angle 23.9$ & $\begin{array}{l}155 \angle- \\
139.2\end{array}$ & $18 \angle-18$ & $253 \angle-127.5$ & $234 \angle-94.2$ & $1136 \angle-38.8$ \\
\hline 8 & $13 / 6 / 2015$ & 11.45 & $\begin{array}{l}\text { Zone } 2 \\
\mathrm{ABC}\end{array}$ & $\begin{array}{l}\text { BK } 1 \text { \& } \\
\text { BK } 2 \\
\text { Open }\end{array}$ & $29 \angle-0.3$ & $29 \angle-120.3$ & $29 \angle 119.7$ & $1600 \angle 95.4$ & $1600<-24.6$ & $1600<-144.6$ \\
\hline 9 & $6 / 3 / 2015$ & 33.79 & $\begin{array}{l}\text { Zone } 3 \\
\text { C-GND }\end{array}$ & $\begin{array}{l}\text { BK } 1 \text { \& } \\
\text { BK } 2 \\
\text { Open }\end{array}$ & $\begin{array}{l}157 \angle \\
18.1\end{array}$ & $\begin{array}{l}152 \angle- \\
140.8\end{array}$ & $22 \angle 118.7$ & $603 \angle-151.8$ & $172 \angle-169.8$ & $1519 \angle 33.4$ \\
\hline
\end{tabular}

\section{B. Modelling the Power System Network}

The parameters of the power system to be modelled is shown in the table below.

TABLE III: POWER SYSTEM PARAMETERS

\begin{tabular}{lll}
\hline \hline Parameters & Parameter Description & Parameter Value \\
\hline $\mathrm{V}$ & Nominal System Line-Line Voltage & $330 \mathrm{kV}$ \\
$\mathrm{I}$ & Nominal Relay Current & $1 \mathrm{~A}$ \\
$\mathrm{~F}$ & Nominal Frequency & $50 \mathrm{~Hz}$ \\
$\mathrm{~L}$ & Alaoji-Afam Line Length & $25 \mathrm{Km}$ \\
$\mathrm{VTR}$ & Voltage Transformer Ratio & $330000: 110=3000 \mathrm{~V}$ \\
$\mathrm{CTR}$ & Current Transformer Ratio & $1600: 1=1600 \mathrm{~A}$ \\
$\mathrm{Z}_{\mathrm{L} 1}(\mathrm{mag})$ & Positive Sequence Impedance (Magnitude) Alaoji-Afam Line & $4.10 \Omega$ \\
$\mathrm{Z}_{\mathrm{L} 1}(\mathrm{ang})$ & Positive Sequence Impedance (Phase Angle) Alaoji-Afam Line & $82.7 \mathrm{Deg}$ \\
$\mathrm{Z}_{\mathrm{L} 0}(\mathrm{mag})$ & Zero Sequence Impedance (Magnitude) Alaoji-Afam Line & $13.81 \Omega$ \\
$\mathrm{Z}_{\mathrm{L} 0}($ ang) & Zero Sequence Impedance (Phase Angle) Alaoji-Afam Line & $75.40 \mathrm{Deg}$ \\
Conductor & Bison 2*350mm2 & \\
\hline \hline
\end{tabular}




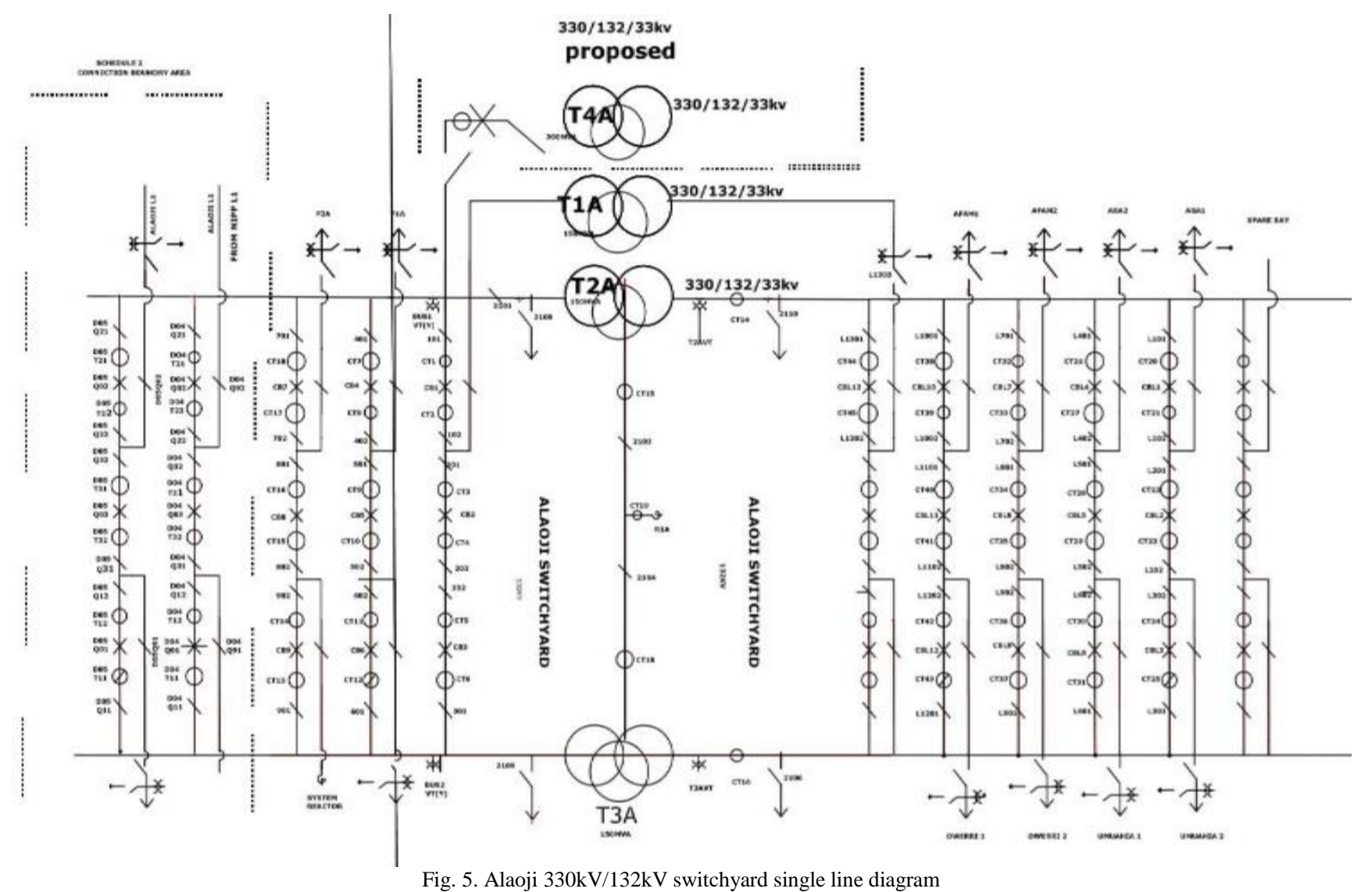

\section{Relay Switch Setting}

Positive sequence impedance (Rectangular form):

$Z_{1}=0.5211+j 4.06679 \Omega$

Zero sequence impedance (Rectangular form):

$Z_{0}=3.4815+j 13.3639 \Omega$

TABLE IV: RELAY REACH AND TIME DELAY SETTING

\begin{tabular}{lll}
\hline \hline Name & Reach Setting $(\Omega)$ & $\begin{array}{l}\text { Time Delay } \\
\text { Setting }(\mathrm{ms})\end{array}$ \\
\hline Zone 1 & $3.28 \angle 82.6$ & 0 \\
Zone 2 & $8.53 \angle 82.7$ & 450 \\
Zone 3 & $12.7 \angle 82.7$ & 750 \\
\hline \hline
\end{tabular}

D. Description of Alaoji 330kV Transmission substation

From the network diagram shown in Fig. 5, Alaoji substation has two switchyards namely:

- Alaoji switchyard 330kV

- Alaoji switchyard 132kV

$330 \mathrm{kV}$ received, enters Alaoji switchyard through its double busbars and move straight to T2A and T3A 150 MVA power transformers. These transformers step down the voltage from $330 \mathrm{kV}$ to $132 \mathrm{kV}$ and fed into $132 \mathrm{kV}$ switchyard. The $330 \mathrm{kV}$ received enters Alaoji station through double bus-bar arrangement. Isolators, CTs, VTs, relays, circuit breakers etc. Power is evacuated from $330 \mathrm{kV}$ Alaoji switchyard through F2A and F1A to the national grid. Afam substation receives power from Alaoji substation.

\section{E. Distance Relay Algorithm Flowchart}

Fast Fourier Transform (FFT) is used to evaluate fundamental components such as positive sequence impedance, symmetrical components etc and require Fast Fourier Transformer (FFT). FFT is a fast algorithm for correct computation of Discrete Fourier Transform (DFT). The relay to be modeled follows the algorithm shown in Fig. 6 below.

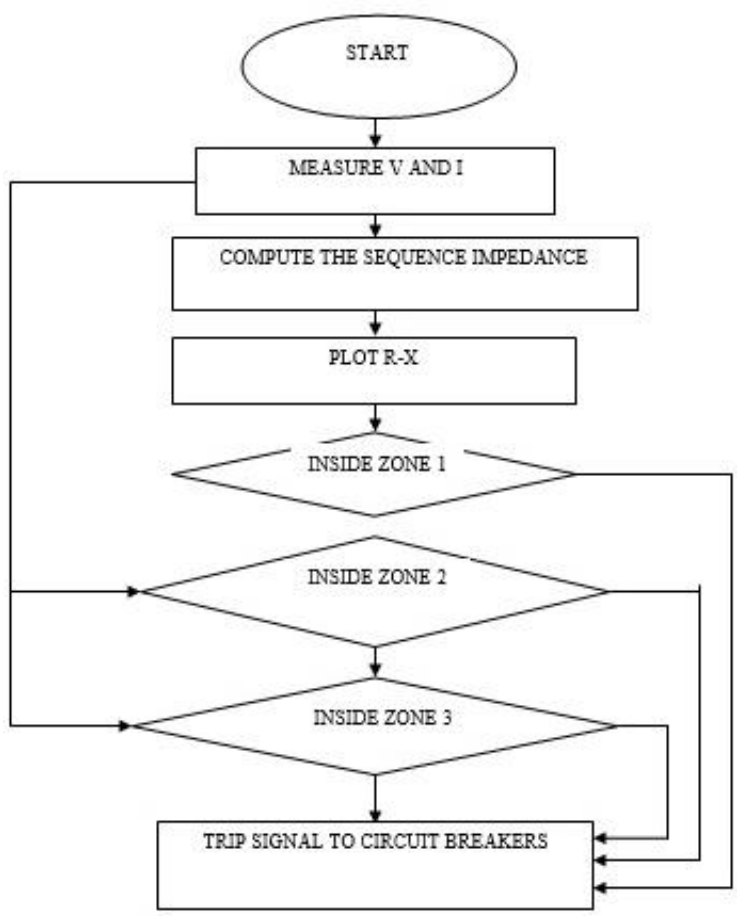

Fig. 6. Relay Algorithm Flow Chart 
The algorithm will operate as follows:

$>$ Voltage and current are fed into the FFT of NEPLAN as input signals to evaluate sequence impedance, especially positive sequence.

$>$ Polygon characteristics is drawn ( $\mathrm{R}-\mathrm{X}$ diagram)

$>$ Under fault, if the measured impedance is inside zone-1, the relay sends tripping signal to open the breakers, and if it is not, R-X plot will move on to zone-2.

$>$ Under fault, if measured impedance is inside zone-1, the relay sends tripping signal to open the breakers, and if it is not, R-X plot will move on to zone-2.

$>$ If the measured impedance is inside zone-2, tripping signal is sent by the relay to the circuit breakers, and if it is not, the R-X plot will move on to zone 3

$>$ If the measured impedance is inside zone-3, then the relay sends tripping signal to circuit breakers, and if it is not in zone-1, zone-2, nor zone-3, the system is not under any fault (stable).

\section{SHORT CirCUIT CALCULATIONS}

Network consisting of pre-fault voltage source UOk and network impedance $\mathrm{ZKi}$ for positive, negative and zero sequence network at the faulted node is used to represent power system behavior during short circuit. The equations are dependent on fault type and are shown. 3-phase fault is balanced and has no negative and zero sequence currents.

\section{A. Three Phase Short Circuit}

$I K_{1}^{\prime \prime}=\frac{U O_{K}}{Z K_{1}}$

$I K_{2}{ }^{\prime \prime}=0$

$I K_{0} "=0$

\section{B. Single Phase to Ground Short Circuit}

$I K_{1}^{\prime \prime}=\frac{U O_{K}}{Z K_{1}+Z K_{2}+Z K_{0}}$

$I K_{2}{ }^{\prime \prime}=I K_{1} "$

$I K_{0}{ }^{\prime \prime}=I K_{1} "$

\section{2-Phases Short Circuit}

$I K_{1}^{\prime \prime}=\frac{U O_{K}}{Z K_{1}+Z K_{2}}$

$I K_{2} "=I K_{1} "$

$I K_{0} "=0$

\section{2-Phases to Ground Short Circuit}

$I K_{1}^{\prime \prime}=\frac{\mathrm{UO}_{K} \cdot\left(\mathrm{ZK}_{2}+\mathrm{ZK}_{0}\right)}{\mathrm{ZK}_{1} \cdot\left(\mathrm{ZK}_{2}+\mathrm{ZK}_{0}\right)+\mathrm{ZK}_{2} \cdot \mathrm{ZK}_{0}}$

$I K_{2} "=-\mathrm{IK}_{1} " \cdot \frac{Z K_{0}}{\left(Z K_{2}+Z K_{0}\right)}$

$I K_{0} "=-\mathrm{IK} \mathrm{K}_{1} \cdot \frac{Z K_{2}}{\left(Z K_{2}+Z K_{0}\right)}$

where:

$\mathrm{UO}_{\mathrm{K}}$ : Operating voltage or pre-fault voltage at faulted node $\mathrm{k}$.

$\mathrm{ZK}_{\mathrm{i}}$ : Network impedances at faulted node of positive $(\mathrm{i}=1)$, negative $(\mathrm{i}=2)$ and zero $(\mathrm{i}=0)$ sequence system.

$\mathrm{IK}_{\mathrm{i}}$ : Initial short circuit current at faulted node of positive $(i=1)$, negative $(i=2)$, and zero $(i=0)$ sequence system.

The network impedances $Z_{1}, Z_{1}$, and $Z K_{0}$ can be computed from the network equation

\section{E. The Initial Short Circuit power SK}

Initial short circuit power (SK) calculation is dependent on the kind of fault:

Symmetrical fault SK' $=\sqrt{3} \cdot U_{n} \cdot|I K|$

Asymmetrical fault SK' $=U_{n} \cdot \frac{|I K|}{\sqrt{3}}$

where: $U_{n}$ means nominal system voltage

\section{BUILDING Distance RELAy MODEL}

Distance relay model is built using NEPLAN using the parameters in Table II, the relay reach setting and the short circuit equations. This is shown below.

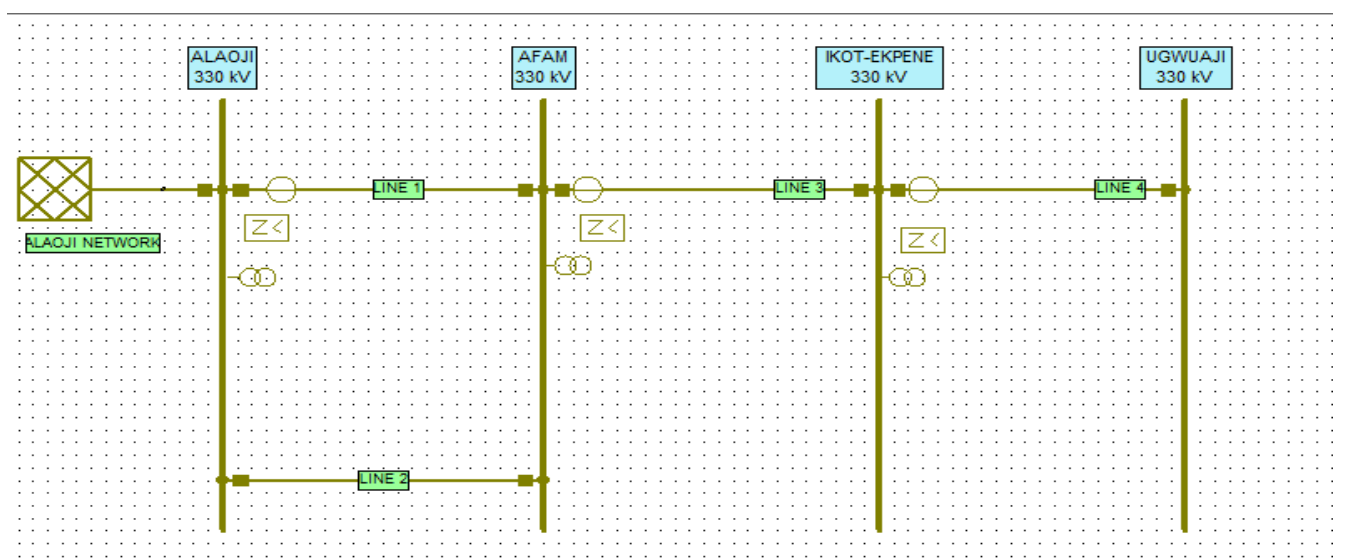

Fig. 7. Alaoji-Afam Distance Relay Model 


\section{Simulation AND ANALYSIS OF RESUlts}

Relay operating behavior depends on whether the impedance trajectory of fault enters its protection zone or not. When the distance relay identifies fault within its zone of operation, it issues trip signal to the circuit breaker to isolate the faulty part of the network from the healthy one.

\section{A. Case 1: 3-Phase Fault Without Arc Resistance $\left(R_{f}\right)$}

3-Phase faults at different locations on $330 \mathrm{kV}$ network were first determined after which fault resistances of different values were introduced, were also simulated using NEPLAN software. it develops 3-zone polygon characteristic to represent zones protection. The characteristics of distance relay is plotted on an $\mathrm{R}-\mathrm{X}$ diagram where; $\mathrm{R}$ and $\mathrm{X}$ represents resistance and reactance respectively. Simulation results are shown in the tables below. The model and its impedance trajectory are shown in the figures below.

TABLE V: Result OF 3-PhASE FAUlt AT 80\% FROM ALAOJI Bus, ZoNE 1

\begin{tabular}{cccccccccc}
\hline \hline Name & Fault & Distance & ZR & ZR Angle & UR & UR Angle & IR & IR Angle & TI \\
\hline & & $\%$ & $\Omega$ & & $\mathrm{kV}$ & & $\mathrm{Ka}$ & & $\mathrm{ms}$ \\
Line 1 & $3 \mathrm{p}$ & 80 & 3.28 & 82.7 & 9.064 & -7 & 2.763 & -89.9 & 300 \\
\hline \hline
\end{tabular}

TABLE VI: RESUlt of 3-PHASE FAUlt AT 30\% FROM AFAM Bus, ZONE 2

\begin{tabular}{ccccccccccc}
\hline \hline Name & Fault & Distance & ZR & ZR Angle & UR & UR Angle & IR & IR Angle & TI & T2 \\
\hline & & $\%$ & $\Omega$ & & $\mathrm{kV}$ & & $\mathrm{Ka}$ & & $\mathrm{ms}$ & $\mathrm{ms}$ \\
Line 3 & $3 \mathrm{p}$ & 30 & 5.97 & 82.7 & 13.448 & -6.8 & 2.252 & -89.5 & 450 & 320 \\
\hline \hline
\end{tabular}

TABLE VII: Result of 3-PhASE FAULT AT 6\% From IKOT-EKPENE Bus, ZoNE 3

\begin{tabular}{|c|c|c|c|c|c|c|c|c|c|c|c|}
\hline Name & Fault & Distance & ZR & ZR Angle & UR & UR Angle & IR & IR Angle & TI & $\mathrm{T} 2$ & T3 \\
\hline & & $\%$ & $\Omega$ & & $\mathrm{kV}$ & & $\mathrm{Ka}$ & & $\mathrm{ms}$ & $\mathrm{ms}$ & $\mathrm{ms}$ \\
\hline Line 4 & $3 p$ & 6 & 10.84 & 82.7 & 23.22 & 233.5 & $2 . .141$ & -89.2 & 750 & 500 & 300 \\
\hline
\end{tabular}

where:

Distance - distance to fault point in percentage;

$$
Z R=\frac{V_{A}}{I_{A}}
$$

$\mathrm{ZR}$ - Impedance measured by the relay during 3-phase fault; $\mathrm{UR}=\mathrm{V}_{\mathrm{A}}-\mathrm{A}$-phase voltage measured during 3-phase fault; $I R=I_{A}-A$-phase current measured during 3-phase fault

$\mathrm{T} 1, \mathrm{~T} 2$, and $\mathrm{T} 3$ are time delays of distance relays in zones 1,2 , and 3 respectively.

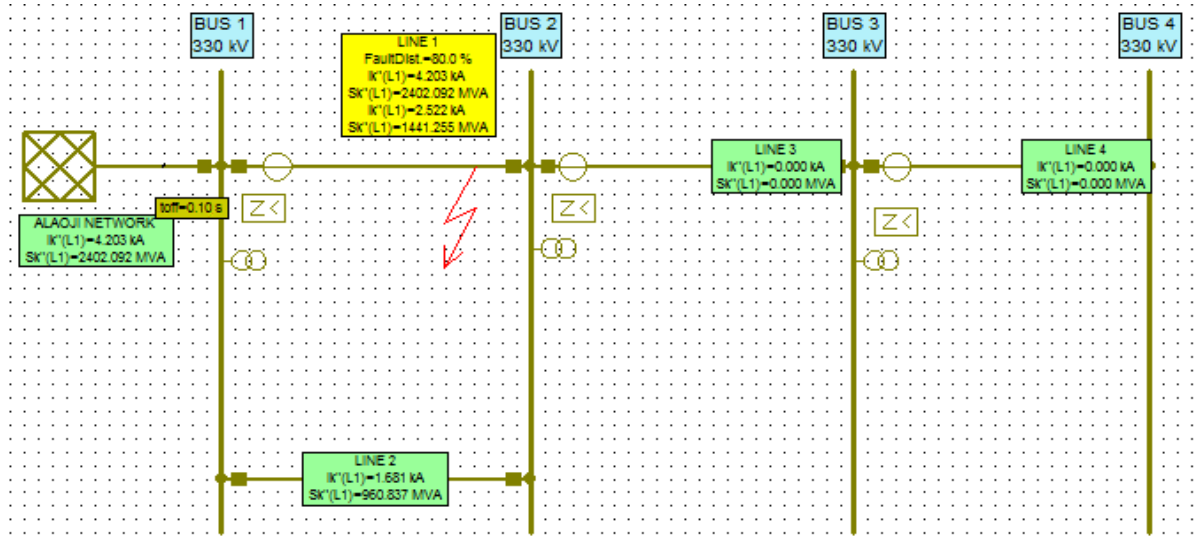

Fig. 8. 3-Phase Fault at $80 \%$ from the location of Alaoji Bus, Zone 1

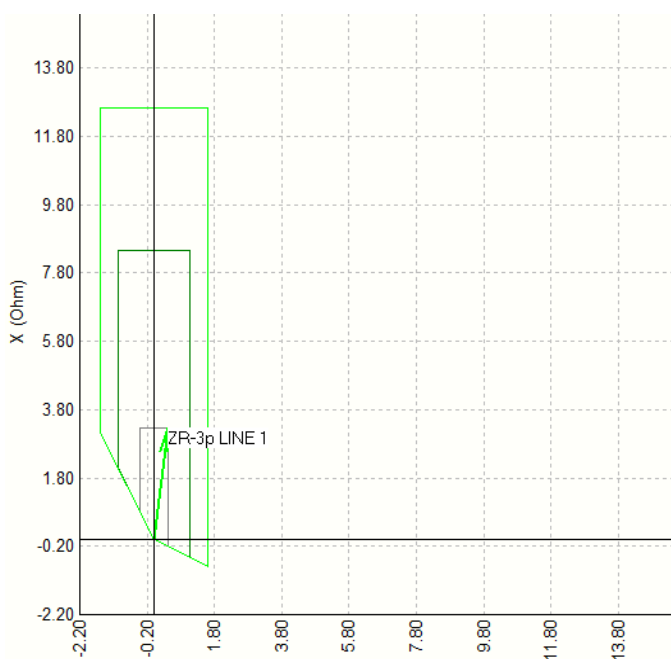

Fig. 9. 3 -Phase Fault at $80 \%$ of the line from the location of Alaoji Bus, Zone 1

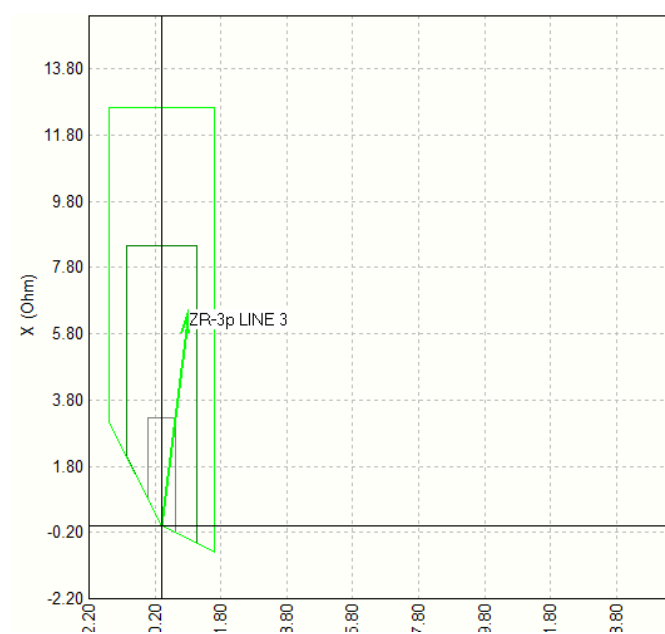

Fig.10. 3 - Phase Fault at $30 \%$ of the line from the location of Afam Bus, Zone 2 


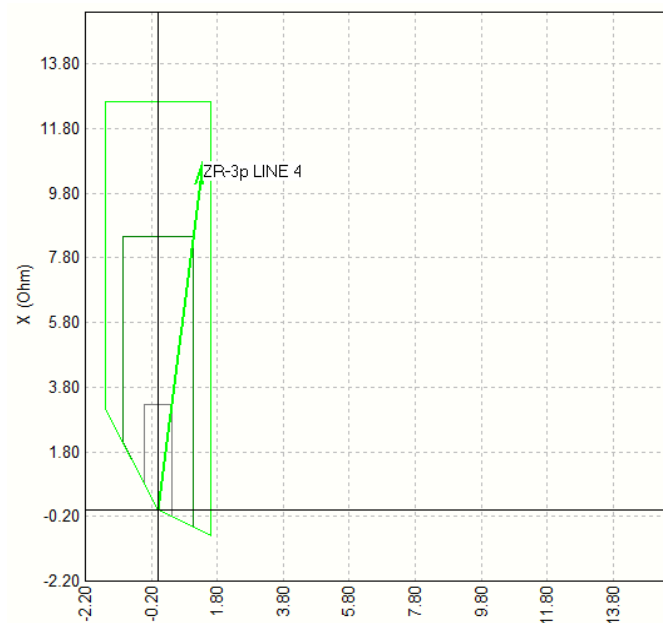

Fig.11. 3-Phase Fault at $6 \%$ of the line from the location of Ikot-Ekpene Bus, Zone 3

Referring to Fig. 8-11 which showed results of 3-phase faults without fault resistance on transmission lines at $80 \%$, $30 \%$, and $6 \%$ from the locations of Alaoji, Afam and IkotEkpene buses respectively. The following were deduced;

1. The apparent impedances (ZR) obtained at various percentage locations $(80 \%, 30 \%$, and $6 \%)$ respectively, fell into their appropriate zones of R-X (refer to Fig. 9, Fig. 10 and Fig. 11). The characteristics showed correct operation of distance relays.

2. The operating times of distance relays for 3-phase faults at $80 \%$ from bus $1,30 \%$ from bus 2 and $6 \%$ from bus 3 respectively are within range of relay time delay settings showing correct operation.

3. Distance relay closest to fault operated first before relays far away from fault location. For instance, fault at $6 \%$ from bus 3 (refer to Fig. 11), the relay in zone 3 operated first while relays in zones 2 and 1 had some time delay. If fault in zone 3 continue to exist, the relay in zone 2 will operate and if it continues the relay in zone 1 will now operate to isolate the fault. The relays in zone 2 and 1 are back up to the relay in zone 3 .

4. No two relays operated at the same time and this showed good co-ordination

5. The modelled distance relay could identify fault locations, type of fault on the lines and zone where fault has occurred.

6. Fault data obtained will enable the protection personnel to locate fault easily and restore the power in the event of fault

B. Case 2: Simulation of 3-Phase Fault with Resistance $\left(R_{F}\right)$

Three-phase fault with fault resistance of $0.4 \Omega, 0.65 \Omega$ and $1.0 \Omega$ respectively, were introduced on the transmission line at distance of $80 \%$ from Alaoji bus. Results are shown in Tables and the impedance trajectory shown in the figure below.

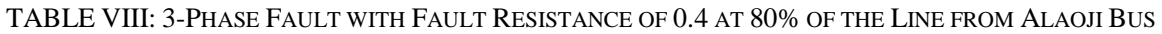

\begin{tabular}{ccccccccc}
\hline \hline Name & Fault & Distance & ZR & ZR Angle & UR & UR Angle & IR & IR Angle \\
\hline & & $\%$ & $\Omega$ & & $\mathrm{kV}$ & & $\mathrm{Ka}$ & \\
Line 1 & $3 \mathrm{p}$ & 80 & 3.367 & 75.1 & 9.303 & -14.2 & 2.763 & -89.2 \\
\hline \hline
\end{tabular}

TABLE IX: 3-PHASE FAULT WITH FAULT RESISTANCE OF 0.65 AT 80\% OF THE LINE FROM ALAOJI BUS

\begin{tabular}{ccccccccc}
\hline \hline Name & Fault & Distance & ZR & ZR Angle & UR & UR Angle & IR & IR Angle \\
\hline & & $\%$ & $\Omega$ & & $\mathrm{kV}$ & & $\mathrm{Ka}$ & \\
Line 1 & $3 \mathrm{p}$ & 80 & 3.583 & 65.3 & 9.897 & -23.6 & 2.762 & -88.9 \\
\hline \hline
\end{tabular}

TABLE X: 3-PHASE FAULT WITH FAULT RESISTANCE OF 1 AT 80\% OF THE LINE FROM ALAOJI BUS

\begin{tabular}{ccccccccc}
\hline \hline Name & Fault & Distance & ZR & ZR Angle & UR & UR Angle & IR & IR Angle \\
\hline & & $\%$ & $\Omega$ & & $\mathrm{kV}$ & & $\mathrm{Ka}$ & \\
Line 1 & $3 \mathrm{p}$ & 80 & 3.863 & 57.4 & 10.67 & 209 & 2.762 & -88.4 \\
\hline \hline
\end{tabular}

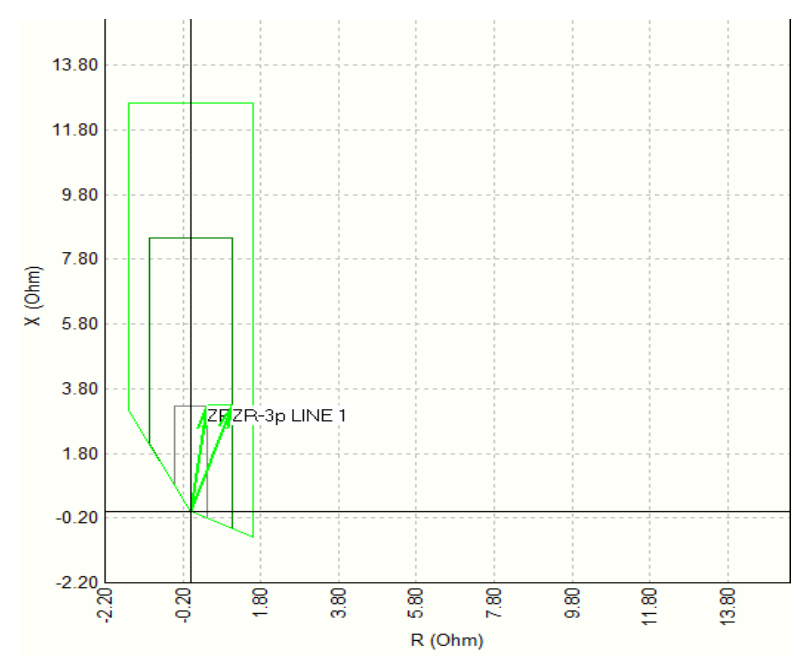

Fig.12. 3-Phase fault with fault resistance of $0.4 \Omega$ at $80 \%$ of the line from Alaoji bus

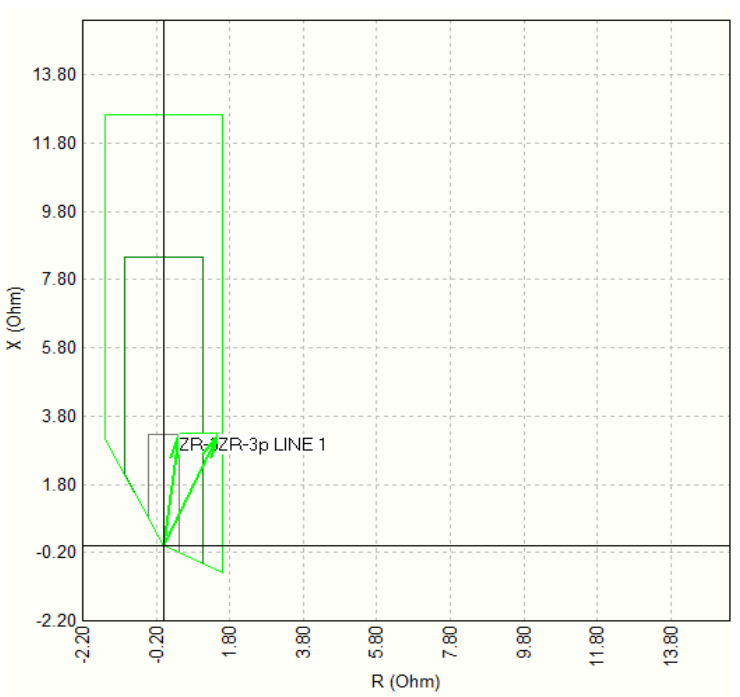

Fig.13. 3-Phase fault with fault resistance of $0.65 \Omega$ at $80 \%$ of the line from Alaoji bus 


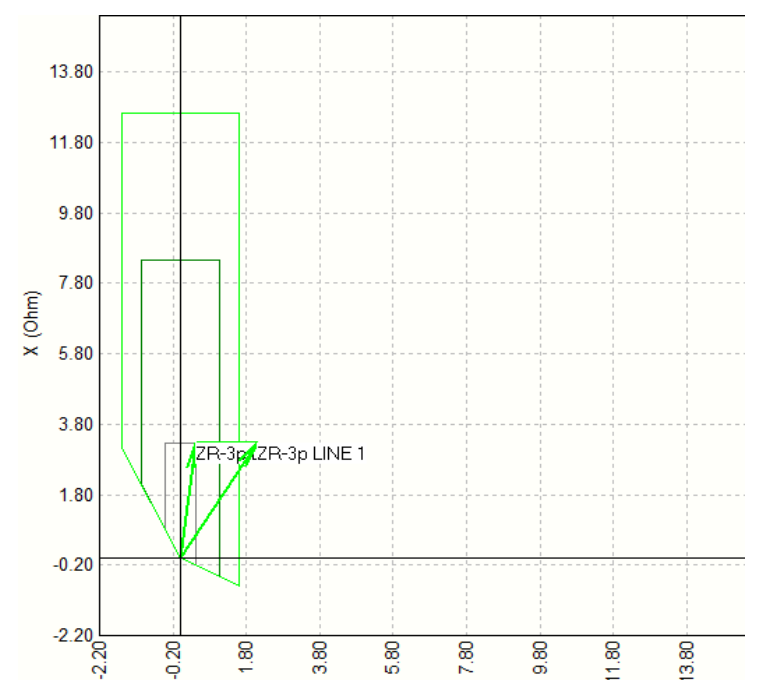

Fig 14. 3-Phase fault with fault resistance of $1 \Omega$ at $80 \%$ of the line from Alaoji bus

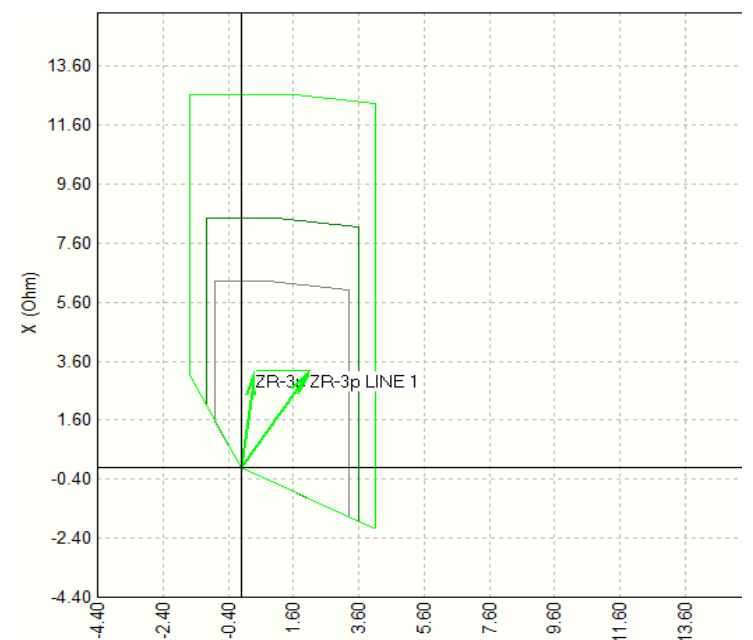

Fig.15. 3-Phase fault with fault resistance of $1 \Omega$ and an increase in zone 1

Referring to Tables XIII, IX and X above which shows results of 3-phase faults with fault resistance of $0.4 \Omega, 0.65 \Omega$ and $1.0 \Omega$ introduced on the transmission line at $80 \%$ of the line from the location of Alaoji bus, respectively. The following were deduced;

1. Introduction of fault resistance $\left(R_{F}\right)$ caused the apparent impedance to increase from its normal value of $3.28 \Omega$ to a higher value.

2. As the fault resistance increased, the apparent impedance also increased causing the relay to underreach. That is, fault which occurred at $80 \%$ of the line which is zone 1 , is detected in zone 2 and zone 3 if the fault resistance increases the more. This is shown in Fig. 11 and Fig 12.

3. The apparent impedance angles $75.1^{\circ}, 65.3^{\circ}$ and $57.4^{\circ}$ measured by the relay showed deviation from the line angle which is 82.7 . This is due to fault resistance introduced. This is also seen in the characteristics shown in Fig. 12, Fig. 13, and Fig. 14.

4. Fault resistance makes apparent impedance no longer appear at the line angle thereby causing underreach. Underreach causes distance relays to give faulty impedance measurement.

5. Further increase in fault resistance to $1 \Omega$ as shown in Fig. 14, the apparent impedance is seen outside the zone of protection. This simply implies that the distance relay will not operate at fault impedance of $1 \Omega$ and the line is unprotected.

6. The performance of distance relay is greatly affected at high fault impedance. Results obtained are generally as expected noting that at high fault resistance, the relay fails to operate in its operating zone

7. The characteristic in Fig. 15 shows that there was significant fault resistance, but due to increase in zone 1 reach to $3.4 \Omega$ and resistive reach coverage of $5 \Omega$, the relay could detect it in zone 1 despite the underreach level. This is a way of compensating for fault resistance introduced and thereby preserving the integrity of the protection scheme.

\section{CONCLUSION AND RECOMMENDATION}

In this work, relay operating behavior of Alaoji 330kV transmission line was investigated to ascertain the efficiencies of various zones of protection. NEPLAN power systems simulation software was used to carry out this analysis. It should be noted that the operating behavior of relays depends on its impedance trajectory of faults (i.e. whether it enters the protection zone or not). Various cases were studied. These include 3-phase fault with and without arc resistance occurring at different locations in the area under study. Three zone polygon characteristics to represent zones of protection and to know the relay characteristics was developed through plot of distance relay in $\mathrm{R}-\mathrm{X}$ diagram. Results of 3-phase faults at $80 \%, 30 \%$ and $6 \%$ from Alaoji, Afam and Ikot Ekpene were obtained and the impedance values were $3.28 \Omega, 5.97 \Omega$ and $10.84 \Omega$ at voltages of $9.064 \mathrm{kV}, 13.45 \mathrm{kV}$ and $23.22 \mathrm{kV}$ respectively. The tripping time is $300 \mathrm{~ms}$ for zone $1,450 \mathrm{~ms}$ and $320 \mathrm{~ms}$ for zone 2 while zone 3 are $750 \mathrm{~ms}, 500 \mathrm{~ms}$ and $300 \mathrm{~ms}$.the current values for these zones were $2.76 \mathrm{kA}, 2.25 \mathrm{kA}$ and $2.14 \mathrm{kA}$. Operation time of distance relay was found to be within range thus showing correct operation of the relay and coordination at various zones (1,2 and 3) as no two relays operated at the same time. If this model is applied in the existing network, challenges such as poor relay coordination/operation due to fault will be a thing of the past. When 3-phase fault with arc resistance of $0.4 \Omega, 0.65 \Omega$ and $1.0 \Omega$ at $80 \%$ of the transmission line, its impedances were $3.37 \Omega, 3.5 \Omega$ and $3.86 \Omega$ respectively, while the bus voltages were $9.30 \mathrm{kV}, 9.89 \mathrm{kV}$ and $10.67 \mathrm{kV}$. The current was obtained to be $2.76 \mathrm{Ka}$ and was same for the three zone (1, 2 and 3). Thus, introducing of fault resistance $\left(\mathrm{R}_{\mathrm{F}}\right)$ caused the apparent impedance to increase from its normal value to a higher value. As the fault resistance increased, the apparent impedance also increased causing the relay to underreach. That is, fault which occurred at $80 \%$ of the line which is zone 1 , is detected in zone 2 and zone 3 if the fault resistance increases the more as shown in the figures. Fault resistance makes apparent impedance not to appear at the line angle thereby causing underreach. Resulting wrong measurement by distance relays. More so, increasing fault resistance to $1 \Omega$ results in the apparent impedance to see fault outside the zone of protection, thus making the distance relay not to operate at fault impedance of $1 \Omega$ and the line is unprotected. The characteristics in Fig. 15 shows that there was significant fault resistance, but due to increase in zone 1 reach to $3.4 \Omega$ and resistive reach coverage of $5 \Omega$, the relay could detect it in zone 1 despite the underreach 
level. This is a way of compensating for fault resistance introduced and thereby preserving the integrity of the protection scheme.

In this work, quadrilateral relay model was done using NEPLAN. Performance characteristics of quadrilateral relay was evaluated at different locations with phase fault and single line to ground fault. Suitable reach has been achieved for setting distance relays used for protecting Alaoji-Afam $330 \mathrm{kV}$ transmission line to achieve selectivity and reliability. If the reach of protected line is increased to $3.4 \angle 82.6 \Omega$ and then use a resistive coverage of5 $\Omega$, the effects of fault resistance will be compensated, and the integrity of our protection scheme is preserved. Therefore, Protection Engineers in substations should endeavor to increase the reach of distance relay protecting Alaoji-Afam $330 \mathrm{kV}$ transmission line to $3.4 \angle 82.6 \Omega$.

For Alaoji-Afam line protection, fault resistance of $2 \Omega$ added to single line-to-ground fault will cause distance relay not to operate and thus leave the line unprotected and cause stress on the power system as the fault stays for a longer time before it is cleared. This might lead to damage of expensive power system equipment. For 3-phase line faults, presence of fault resistance of $1 \Omega$ will cause distance relay not to operate

The developed quadrilateral characteristics may be used to enhance the skills of young and inexperienced engineers, technicians, and students.

The following are recommended:

- It is recommended that zone 1 reach should be increased to $3.4 \angle 82.6 \Omega$ and resistive reach coverage of $5 \Omega$ to preserve the integrity of the protection system during under reach condition be provided.

- Alaoji-Afam $330 \mathrm{kV}$ transmission line has no pilot protection. It uses only step distance protection scheme. It is recommended that the use of Permissive Overreaching Transfer Trip Scheme (POTT) as the main protection scheme and backed up by a step distance scheme to guarantee a better fault coverage, stability and security of the power system be implemented.

- Distance relays in Alaoji substation use only one distance-measuring unit initially set for zone 1 reach, for zone 2 reach and zone 3 reach. If the fault continues, the reach of single distance measuring unit is switched to zone 2 after T2 time delay and to zone 3 after T3 time delay. However, instead of this method, it is recommended that for several protection zones, several distance measuring units should be used to provide reliability and redundancy. For faults in zone 1 reach area, all the three distance units will operate.

- Regular routine test should be carried out to ensure the integrity of relay scheme as faulty protective devices such as circuit breakers, control cable discontinuity, faulty control knob, circuit breaker pole discordance etc may also constitute fault and thus affect the integrity of the protection scheme and may lead to loss of supply of electrical energy.

\section{REFERENCES}

[1] J. N. Rai and Ajit Kumar Singh, "Modeling and Simulation of Distance Relay for Transmission Line Protection" National Conference on Emerging Trends in Electrical and Electronics Engineering (ETEE-2015), Jamia Millia Islamia, New Delhi, 2015

[2] G. Ziegler, "Numerical Distance Protection Principles and Applications", Wiley and Sons, ISBN 3-89578-266-1, 2006.

[3] Muhd Hafizi Idris, Surya Hardia, and Mohd Zamri Hasana, "Teaching Distance Relay Using Matlab/Simulink Graphical User Interface" Maylaysian Technical Universities Conference on Engineering \& Technology 2012.

[4] G. Omar, H. Elfetori and A. Hawai, "Implementation and Evaluation of a SIMULINK Model of a Distance Relay in MATLAB/SIMULINK”, 2013.

[5] Muhd Hafizi Idris, Mohd Saufi Ahmad, Ahmad Zaidi Abdullah, Surya Hardi, "Adaptive Mho Type Distance Relaying Scheme with Fault Resistance Compensation" IEEE $7^{\text {th }}$ International Power Engineering and Optimization Conference, Langkawi, 2013.

[6] M.P. Thakre, V.S. Kale, "Distance Protection for Long Transmission Line Using PS cad", International Journal of Advances in Engineering \& Technology, IJAET. Vol. 6, Issue 6, pp. 2579-2586, ISSN: 22311963.

[7] Abdlmnam A. Abdlrahem and Hamid H Sher, "Modeling Numerical distance relays using MATLAB/SIMULINK Packages", IEEE Symposium on Industrial Electronics and Applications (ISIEA 2009), Kuala Lumpur, Malaysia.

[8] M. H. Idris, S. Hardi and M. Z. Hassan, "Teaching Distance Relay Using Matlab/Simulink Graphical User Interface”, Malaysian Technical Universities Conference on Engineering and Technology, November 2012

[9] Hadi Sadaat, "Power System Analysis", $3^{\text {rd }}$ Edition, PSA Publishing, ISBN 0984543805, 9780984543809

[10] L.C. Wu, C. W.Liu and C. s. Chen, "Modelling and testing of a digital distance relay using Matlab/Simulink", IEEE 2005.

[11] Kinan Wannous and Petr Toman, "The Development of the Impedance Measured by Distance Relay During Near-to-Generator Short Circuit" IEEE 2015, ISBN - 78-1-4673-6788

[12] Bogdan Kasztenny and Dale Finney, "Fundamentals of Distance Protection”, Switchzer Engineering Laboratories, 2008. 